UCRL-ID-127644

\title{
A Model for Designing Planar Magnetron Cathodes
}

\author{
Manuel Garcia
}

September 30, 1997

This is an informal report intended primarily for internal or limited external distribution. The opinions and conclusions stated are those of the author and may or may not be those of the Laboratory.

Work performed under the auspices of the U.S. Department of Energy by the Lawrence Livermore National Laboratory under Contract W-7405-Eng-48. 


\section{DISCLAIMER}

This document was prepared as an account of work sponsored by an agency of the United States Government. Neither the United States Government nor the University of California nor any of their employees, makes any warranty, express or implied, or assumes any legal liability or responsibility for the accuracy, completeness, or usefulness of any information, apparatus, product, or process disclosed, or represents that its use would not infringe privately owned rights. Reference herein to any specific commercial product, process, or service by trade name, trademark, manufacturer, or otherwise, does not necessarily constitute or imply its endorsement, recommendation, or favoring by the United States Government or the University of California. The views and opinions of authors expressed herein do not necessarily state or reflect those of the United States Government or the University of California, and shall not be used for advertising or product endorsement purposes.

This report has been reproduced directly from the best available copy.

Available to DOE and DOE contractors from the Office of Scientific and Technical Information P.O. Box 62, Oak Ridge, TN 37831

Prices available from (615) 576-8401, FTS 626-8401

Available to the public from the National Technical Information Service

U.S. Department of Commerce 5285 Port Royal Rd. Springfield, VA 22161 


\title{
A model for designing planar magnetron cathodes
}

\author{
Manuel Garcia \\ 30 May 1997
}

Lawrence Livermore National Lab. L-153, POB 808, Livermore, CA 94550 garcia22@1lnl.gov, (510) 422-6017

Planar magnetron cathodes have arching magnetic field lines which concentrate plasma density to enhance ion bombardment and sputtering. Typical parameters are: helium at 1 to 300 milli-torr, 200 to 2000 gauss at the cathode, 200 to 800 volts, and plasma density decreasing by up to ten times within 2 to $10 \mathrm{~cm}$ from the cathode. A 2D, quasineutral, fluid model yields formulas for the plasma density: $n(x, y)$, current densities: $\mathbf{j}(\mathrm{x}, \mathrm{y}), \mathbf{j}_{\mathbf{e}}(\mathrm{x}, \mathrm{y}), \mathbf{j}_{+}(\mathrm{x}, \mathrm{y})$, the electric field: $\mathrm{E}_{\mathrm{y}}(\mathrm{y})$, and the voltage between the cathode surface and a distant plasma. An ion sheath develops between the cathode and the quasineutral flow. The thickness of this sheath depends on processes in the quasineutral flow. Experiments shows that $\mathrm{T}_{\mathrm{e}}$ $(3->8 \mathrm{eV})$ adjusts to ensure that $\alpha_{0} \tau \approx 2.5$ in helium, for ionization rate $\alpha_{0}$ $\left(10^{4} \rightarrow 10^{5} \mathrm{~s}^{-1}\right)$, and electron transit time to the unmagnetized plasma $\tau$ $(10->100 \mu \mathrm{s})$. Helium glow discharge cathode fall $\alpha_{0} \tau$ is about 2.5, though this occurs at much higher voltage.

This work was performed under the auspices of the U.S. DOE by LLNL under contract no. W-7405-Eng-48. 


\section{Introduction}

This report outlines an analytical model of the distribution of plasma in the cathode fall of a planar magnetron cathode. Here I continue commentary on previous work, and introduce an ion sheath model to describe the discharge "dark space" below the magnetron halo. Figure 1 is a schematic of these magnetized cathode falls. A constant density ion sheath extends from the cathode surface to a distance $y *$ of the order of millimeters. The bulk of the cathode fall is the quasi-neutral region with falling density extending to a distance $y_{0}$ of the order of centimeters. Beyond $y_{0}$ the plasma electrons are no longer magnetized, and the plasma is uniform.

\section{Quasi-neutral flow}

The original problem prompting my work was to find the spatial distribution of plasma, and the voltage drop, as a function of arbitrary magnetic field $\mathrm{B}(\mathrm{x}, \mathrm{y})=\mathrm{B}_{\mathbf{x}}(\mathrm{x}, \mathrm{y})+\mathrm{B}_{\mathrm{y}}(\mathrm{x}, \mathrm{y})$, where $\mathrm{x}$ is parallel to the cathode and $y$ is perpendicular. Planar magnetron cathodes were being used to lower the impedance of a discharge device designed for an application other than as a sputtering source. The purpose of the model was to facilitate this engineering. Reference 1 describes the quasi-neutral fluid model of the magnetized cathode fall. Below is a summary of those results.

\section{Summary of Analytical Results}

Equations from reference 1 are shown in the logical sequence for any specific calculation. The equations are numbered exactly as in reference 1 (please see that report for a complete description).

$$
\begin{gathered}
v_{\mathrm{e}}^{2}=\frac{\frac{5 \mathrm{kT}_{\mathrm{e}}}{\mathrm{m}_{\mathrm{e}}}}{2 \frac{v_{\mathrm{eN}}}{\alpha_{0}}-1}=\left(\frac{j_{\infty}}{\mathrm{en}_{\infty}}\right)^{2} \\
\frac{\mathrm{v}_{\mathrm{ez}}}{\mathrm{v}_{\mathrm{ey}}}=\mu_{\mathrm{e}} \mathrm{B}_{\mathrm{x}} \quad \mathrm{v}_{\mathrm{ey}}=\frac{\mathrm{v}_{\mathrm{e}}}{\sqrt{1+\mu_{\mathrm{e}}^{2} \mathrm{~B}_{\mathrm{x}}^{2}}} \quad \mathrm{v}_{\mathrm{ez}}=\frac{\mathrm{v}_{\mathrm{e}} \mu_{\mathrm{e}} \mathrm{B}_{\mathrm{x}}}{\sqrt{1+\mu_{\mathrm{e}}^{2} \mathrm{~B}_{\mathrm{x}}^{2}}}
\end{gathered}
$$




$$
\begin{aligned}
& \mu_{\mathrm{e}} \mathrm{B}_{\mathrm{x}}\left(0, \mathrm{y}_{\infty}\right)=1
\end{aligned}
$$

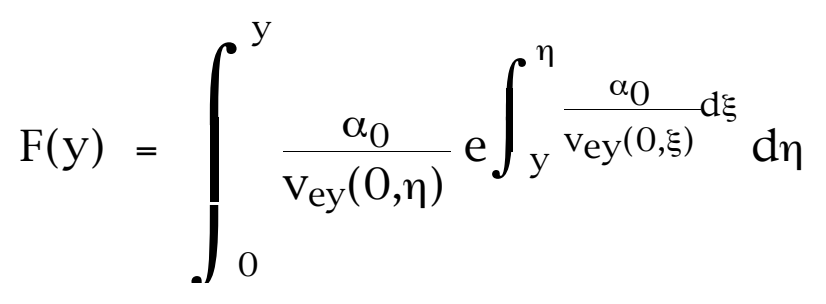

$$
\begin{aligned}
& \mathrm{u}_{\mathrm{e}} \equiv \frac{5 \mathrm{kT}_{\mathrm{e}}}{2 \mathrm{e}}+\frac{\mathrm{mv}_{\mathrm{e}}^{2}}{2 \mathrm{e}} \\
& \phi_{\infty}=\mathrm{u}_{\mathrm{e}}\left(\frac{1}{1-\mathrm{F}\left(\mathrm{y}_{\infty}\right)}-1\right) \\
& \phi(\mathrm{y})=\left(\mathrm{u}_{\mathrm{e}}+\phi_{\infty}\right) \mathrm{F}(\mathrm{y}) \\
& \frac{\mathrm{d} \phi}{\mathrm{dy}}=\frac{\alpha_{0}\left(\mathrm{u}_{\mathrm{e}}+\phi_{\infty}\right)}{\mathrm{v}_{\mathrm{ey}}(0, \mathrm{y})}(1-\mathrm{F}(\mathrm{y}))=-\mathrm{E}_{\mathrm{y}} \\
& \mathrm{v}_{+}^{2}=\frac{2 \mathrm{e}}{\mathrm{m}_{+}}\left(\phi_{\infty}-\phi\right) \\
& \mathrm{n}(\mathrm{x}, \mathrm{y}) \equiv \mathrm{n}_{0}(\mathrm{y}) \mathrm{L}(\mathrm{x}, \mathrm{y}) \quad \mathrm{n}_{0}(\mathrm{y}) \equiv \mathrm{n}\left(-\mathrm{x}_{\mathrm{p}}, \mathrm{y}\right) \\
& n(x, y)=n\left(-x_{p}, y\right) \exp \left[\frac{v_{e}}{D_{e}-D_{+}} \int_{-x p}^{x} \frac{\mu_{e}^{2} B_{x} B_{y}}{\sqrt{1+\mu_{e}^{2} B_{x}^{2}}} d x\right] \\
& \mathrm{a}(\mathrm{y}) \equiv \Delta \mathrm{ze}\left(\mathrm{D}_{\mathrm{e}}-\mathrm{D}_{+}\right) \int_{-\mathrm{x}_{\mathrm{p}}}^{+\mathrm{x}_{\mathrm{p}}} \mathrm{L}(\mathrm{x}, \mathrm{y}) \mathrm{dx} \\
& b(y) \equiv \Delta z e \int_{-x_{p}}^{+x_{p}}\left[L \cdot\left(\mu_{e} E_{y}+\frac{v_{e z}^{2}}{v_{e y}}\right)+\left(D_{e}-D_{+}\right) \frac{\partial L}{\partial y}\right] d x \\
& \mathrm{H}(\mathrm{y}) \equiv \mathrm{b}(\mathrm{y}) / \mathrm{a}(\mathrm{y}) \quad \mathrm{K}(\mathrm{y}) \equiv \mathrm{I}_{0} / \mathrm{a}(\mathrm{y})
\end{aligned}
$$




$$
\begin{aligned}
& \mathrm{n}_{0}(0)=\mathrm{n}_{\infty} \mathrm{e}_{0}^{\mathrm{y}_{\infty}} \mathrm{H}(\eta) \mathrm{d} \eta-\int_{0}^{\mathrm{y}_{\infty}} \mathrm{K}(\eta) \cdot \mathrm{e} \int_{0}^{\eta} \mathrm{H}(\xi) \mathrm{d} \xi \mathrm{d} \eta \\
& \mathrm{n}_{0}(\mathrm{y})=\mathrm{e}^{-\int_{0}^{\mathrm{y}} \mathrm{H}(\eta) \mathrm{d} \eta} \cdot\left[\mathrm{n}_{0}(0)+\int_{0}^{\mathrm{y}} \mathrm{K}(\eta) \cdot \int_{0}^{\eta} \mathrm{H}(\xi) \mathrm{d} \xi \mathrm{d} \eta\right] \\
& I_{M}=\int_{0}^{y_{\infty}} \int_{-x_{p}}^{+x_{p}}-e n(x, y) v_{e z}(x, y) d x d y
\end{aligned}
$$

Besides the magnetic field, the model requires $\mathrm{T}_{e}, \mathrm{j}_{\infty}$ or $\mathrm{n}_{\infty}$, and both $\alpha_{0}$ and $v_{\mathrm{eN}}$ (which depend on $\mathrm{T}_{\mathrm{e}}$ and the gas). The proper $\mathrm{T}_{\mathrm{e}}$ to select for any gas mixture is that which gives the same $\alpha_{0} \tau$ as a glow discharge conveying the same amount of current. Please see reference 2 for a complete discussion on how $\alpha_{0} \tau$, the product of the ionization rate and electron transit time from the cathode to $y_{0}$, allows for a direct comparison of cathode falls from planar magnetron cathodes and glow discharges. Magnetized cathodes operate at lower voltage than glow discharges of equal current because electrons are confined near the cathode for a longer time thus producing the required ionization at lower average energy.

After reference 1 was issued I realized that equation (52) can be stated more simply as:

$$
F(y)=1-\exp \left(-\int_{0}^{y} \frac{\alpha_{0}}{v_{e y}(0, \eta)} d \eta\right)
$$

In practice the lateral limits $\pm x_{p}$ should be taken beyond the poles of the flanking magnets (more generally, beyond the points where $\mathrm{B}_{\mathrm{X}}(\mathrm{x}, 0)=0$ given that $\mathrm{x}=0$ is the center of the magnetron track and halo). These limits appear in equations (59), (58), (64), (65), (68). Both references 1 and 
2 show examples of spatial distributions of density and current calculated from these equations.

\section{Selecting an Ion Sheath}

Electrons near the cathode surface are immobilized by $\mathrm{B}_{\mathrm{x}}(\mathrm{x}, \mathrm{y})$, and an ion sheath forms. Define a Debye length based on ion kinetic energy, $V_{i}$ in $\mathrm{eV}$ :

$$
\mathrm{h}_{\mathrm{D}_{\mathrm{i}}}=\sqrt{\frac{\varepsilon_{0} \mathrm{~V}_{\mathrm{i}}}{\mathrm{e} \mathrm{n}}}
$$

The sheath forms to a distance y from the cathode, where the local density $\mathrm{n}(\mathrm{y})$ and voltage $\mathrm{V}(\mathrm{y})$ (which sets $\mathrm{V}_{\mathrm{i}}$ ) make $\mathrm{h}_{\mathrm{Di}}=\mathrm{y}$. The ion kinetic energy is estimated most simply as $\mathrm{V}_{\mathrm{i}}=\mathrm{V}_{0}-\mathrm{V}(\mathrm{y})$, for $\mathrm{V}_{0}=$ the total voltage drop between the cathode and the end of the magnetized "fall" at $\mathrm{y}_{0}$ [same as $\mathrm{y}_{\infty}$ in reference 1 , defined by equation (53)]. $\mathrm{V}(\mathrm{y})$ rises from zero at the cathode to $\mathrm{V}_{0}$ at $\mathrm{y}=\mathrm{y}_{0} . \therefore$

$$
\mathrm{h}_{\mathrm{D}_{\mathrm{i}}}=\sqrt{\frac{\varepsilon_{0}\left(\mathrm{~V}_{0}-\mathrm{V}(\mathrm{y})\right)}{\mathrm{e} n(\mathrm{y})}}=\mathrm{y}
$$

It is assumed here that only the most dense plasma, between the magnet poles $(\mathrm{X}=0)$, need be considered. Equation (2) is an energy condition for sheath formation: ions must have sufficient kinetic energy to create a charge separation of density $\mathrm{n}$ over a distance $\mathrm{y}$ with electrons immobilized by $B_{x}$.

A unique value of $y$ is determined with the addition of a current conservation condition: (ion current from the sheath $)=($ ion + electron currents from the quasi-neutral flow):

$$
\begin{gathered}
\mathrm{I}_{\mathrm{h}}=\mathrm{I}_{+}+\mathrm{I}_{\mathrm{e}} \\
\Delta \mathrm{Z} \int_{<\text {pole }(-)}^{>\text {pole }(+)} \mathrm{e} \mathrm{n}_{\mathrm{h}}(\mathrm{x}, 0) \mathrm{v}_{\mathrm{h}} \mathrm{dx}=\Delta \mathrm{Z} \int_{<\text {pole }(-)}^{>\text {pole }(+)} \mathrm{e} \mathrm{n}(\mathrm{x}, \mathrm{y} *)\left[\mathrm{v}_{+}+\mathrm{v}_{\mathrm{e}}\right] \mathrm{dx}
\end{gathered}
$$


Assuming that most of the current is conveyed at $\mathrm{x}=0$ (between poles), then the integration over $\mathrm{x}$ can be dropped $(\Delta \mathrm{Z}=$ length of magnetron track), leaving:

$$
e n_{h}(0) v_{h}=e n\left(y_{*}\right)\left(v_{+}+v_{e}\right)
$$

The ion density in the sheath is constant as no ionization occurs because the electrons are immobilized, $\therefore \mathrm{n}_{\mathrm{h}}=\mathrm{n}(\mathrm{y} *)=$ the plasma density at the interface between the sheath and the quasi-neutral flow. All the current at the cathode surface is carried by ions at $V_{i}=V_{0}$, [recall that $V(y=0)=0$, the ions being accelerated through the sheath. Thus the current continuity expression above is simplified to:

$$
\mathrm{v}_{\mathrm{h}}=\sqrt{\frac{2 \mathrm{e} \mathrm{V}}{\mathrm{m}_{+}}}=\sqrt{\frac{2 \mathrm{e}}{\mathrm{m}_{+}}\left(\mathrm{V}_{0}-\mathrm{V}\left(\mathrm{y}_{*}\right)\right)}+\mathrm{v}_{\mathrm{e}}\left(\mathrm{y}_{*}\right)
$$

Here $v_{e}(y)$ is the fluid velocity component in the $+y$ direction.

Now solve for $\mathrm{y} *$ by eliminating $\mathrm{V}_{0}-\mathrm{V}(\mathrm{y})$ from both (2) and (3). The first and then last steps of this algebra are as follows:

$$
\begin{aligned}
& \sqrt{\frac{2 \mathrm{e} V_{0}}{m_{+}}}=\sqrt{\frac{2 \mathrm{e}}{m_{+}}\left(y_{*}^{2} \frac{\mathrm{e} \mathrm{n}\left(\mathrm{y}_{*}\right)}{\varepsilon_{0}}\right)}+\mathrm{v}_{\mathrm{e}}(\mathrm{y} *) \\
& \mathrm{y} *=\sqrt{\frac{\varepsilon_{0} \mathrm{~m}_{+}}{2 \mathrm{e}^{2} \mathrm{n}(\mathrm{y} *)}}\left(\sqrt{\frac{2 \mathrm{e} \mathrm{V}_{0}}{\mathrm{~m}_{+}}}-\mathrm{v}_{\mathrm{e}}(\mathrm{y} *)\right)
\end{aligned}
$$

The sheath starts where quasi-neutral $\mathrm{n}(\mathrm{y})$ and $\mathrm{v}_{\mathrm{e}}(\mathrm{y})$ are related to coordinate $y$ as in equation (4). In this work a simple splice is effected: below $\mathrm{y} *$ is ion sheath, above $\mathrm{y} *$ is quasi-neutral flow. This formula produces a sheath height comparable to the "dark spaces" seen in the experiment. Note that for negligible $\mathrm{v}_{\mathrm{e}}(\mathrm{y} *)$, the expression for $\mathrm{y} *$ reduces to a Debye length formula:

$$
\mathrm{y} *=\sqrt{\frac{\varepsilon_{0} \mathrm{~V}_{0}}{\mathrm{e} \mathrm{n}(\mathrm{y} *)}}
$$


reflecting formula (1) with specific choices for ion kinetic energy and sheath density. These choices are determined by the balance of ionization and transport in the magnetized, quasi-neutral flow.

Reference 3 discusses ion sheaths with magnetized electrons, however the regime of interest in that report was very different than that of sputter discharges. The essential point here is that ions can use their kinetic energy to create a charge separation when electrons are fixed by transverse field lines. The relationship between the ion energy, the charge density and the extent of the separation is the Debye length formula.

\section{Magnet orientation}

Figures 2, 3, and 4 show the types of magnet orientations discussed in reference 2. A magnet whose polar axis is perpendicular to the cathode surface nearest the plasma halo is said to be at $0^{\circ}$. A magnet whose polar axis is parallel to the cathode surface closest to the plasma halo is said to be at $90^{\circ}$. A fin cathode as shown in Figure 4 was found to produce the lowest overall discharge impedance in the experiments described in reference 2 .

\section{References}

1) "A 2D Fluid Model of the DC Planar Magnetron Cathode," UCRL-ID122494, 15 November 1995

2) "Comparing a 2D Fluid Model of the DC Planar Magnetron Cathode to Experiments,” UCRL-ID-125434, 15 May 1996

3) “Electric Vortex in MHD Flow,” UCRL-ID-121162, 1 May 1995

The above are available at:

http://www.llnl.gov/tid/lof/lof_home.html 


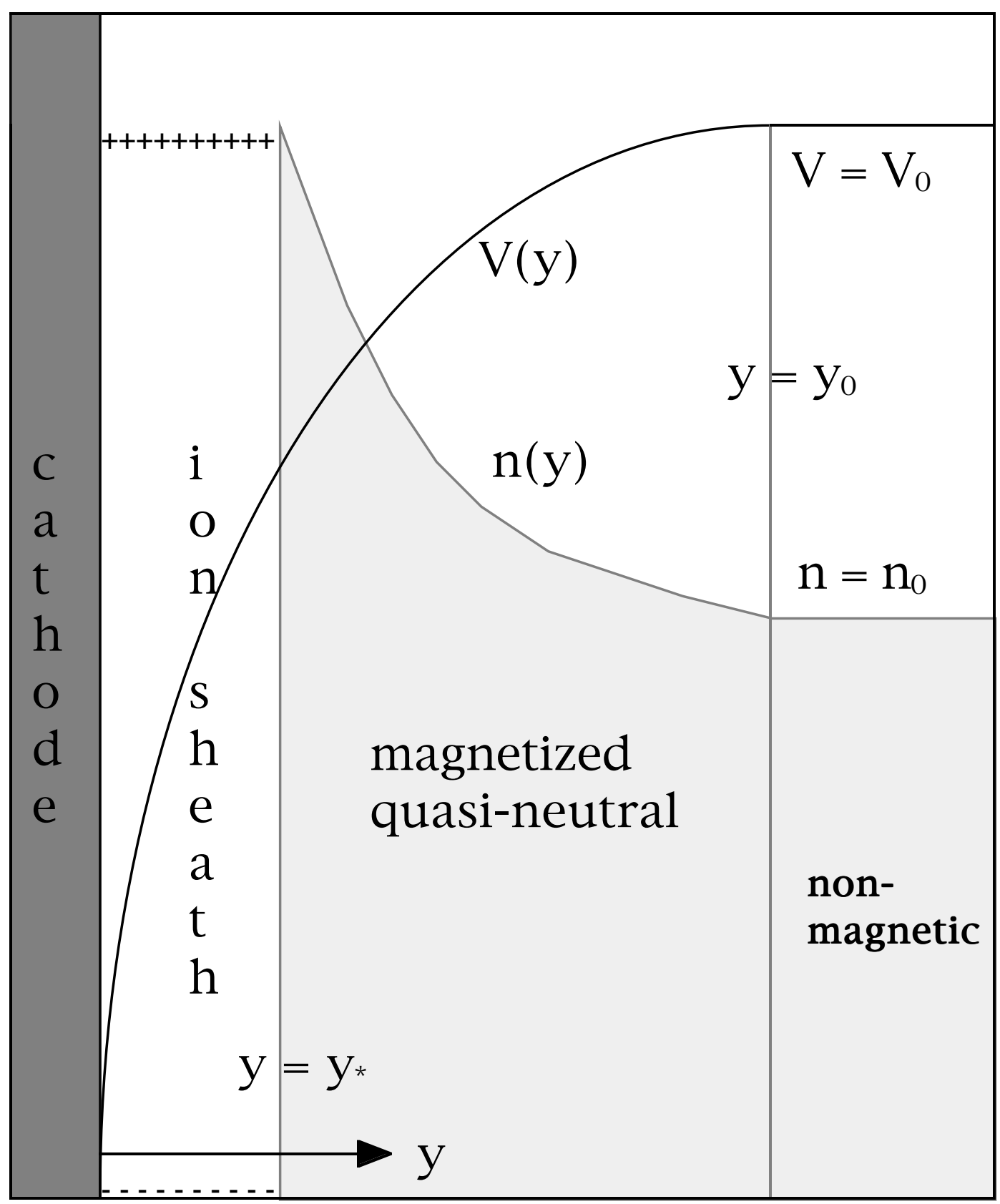

Figure 1: schematic profile of planar magnetron cathode fall 


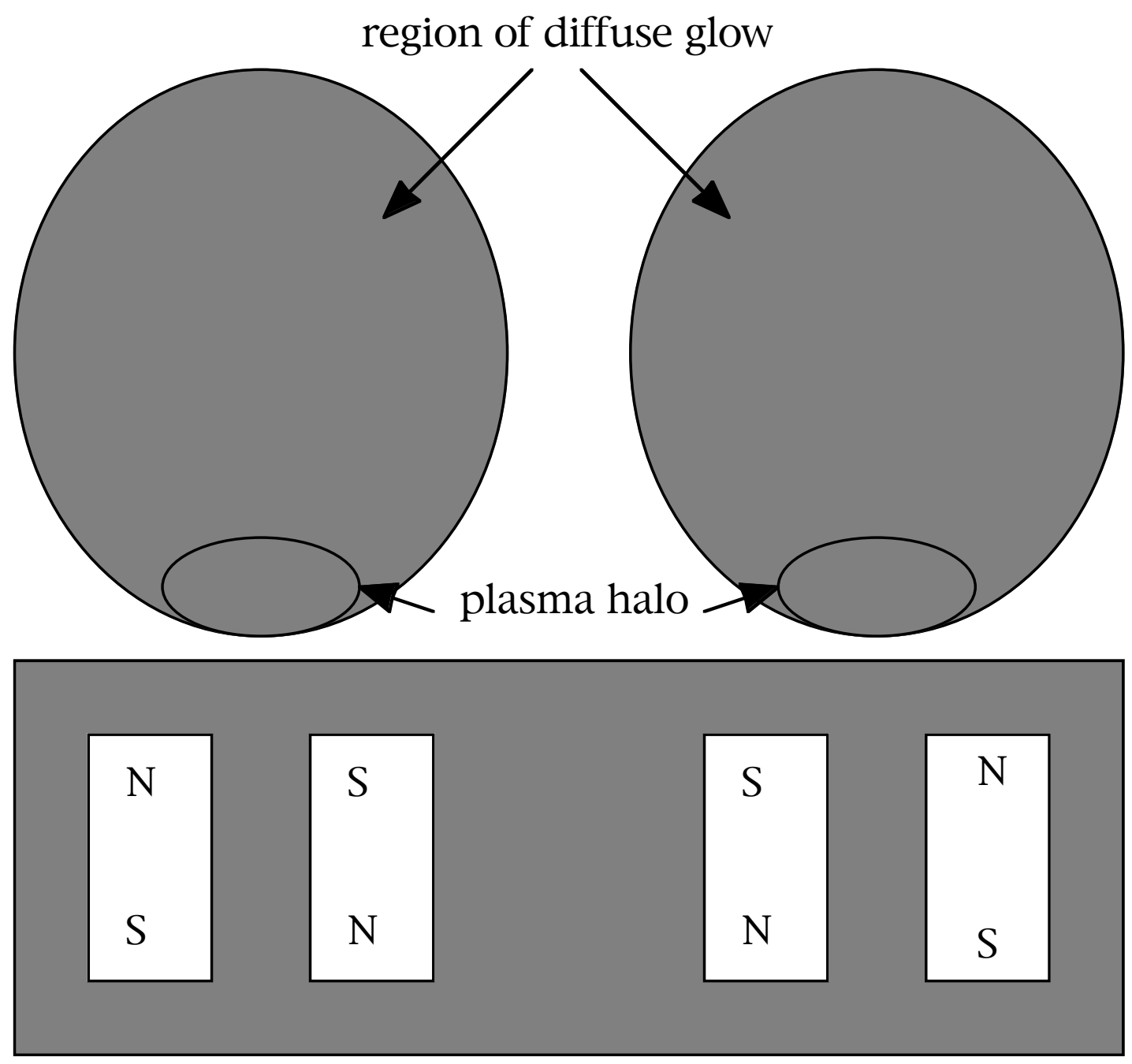

Cross section of a cathode with magnets @ $0^{\circ}$

Figure 2: $0^{\circ}$ cathode 


\section{anode}

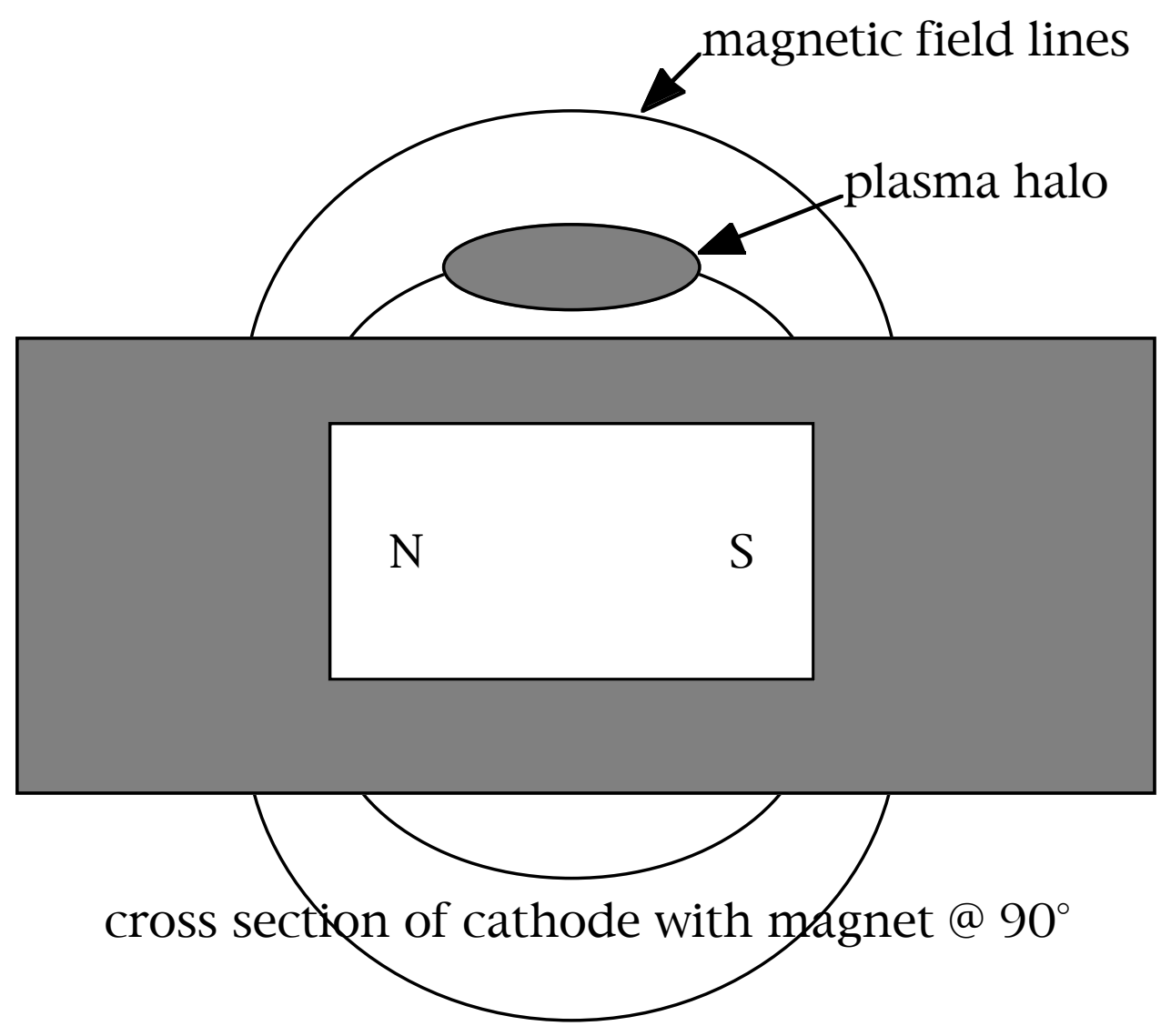

Figure $3: 90^{\circ}$ cathode 

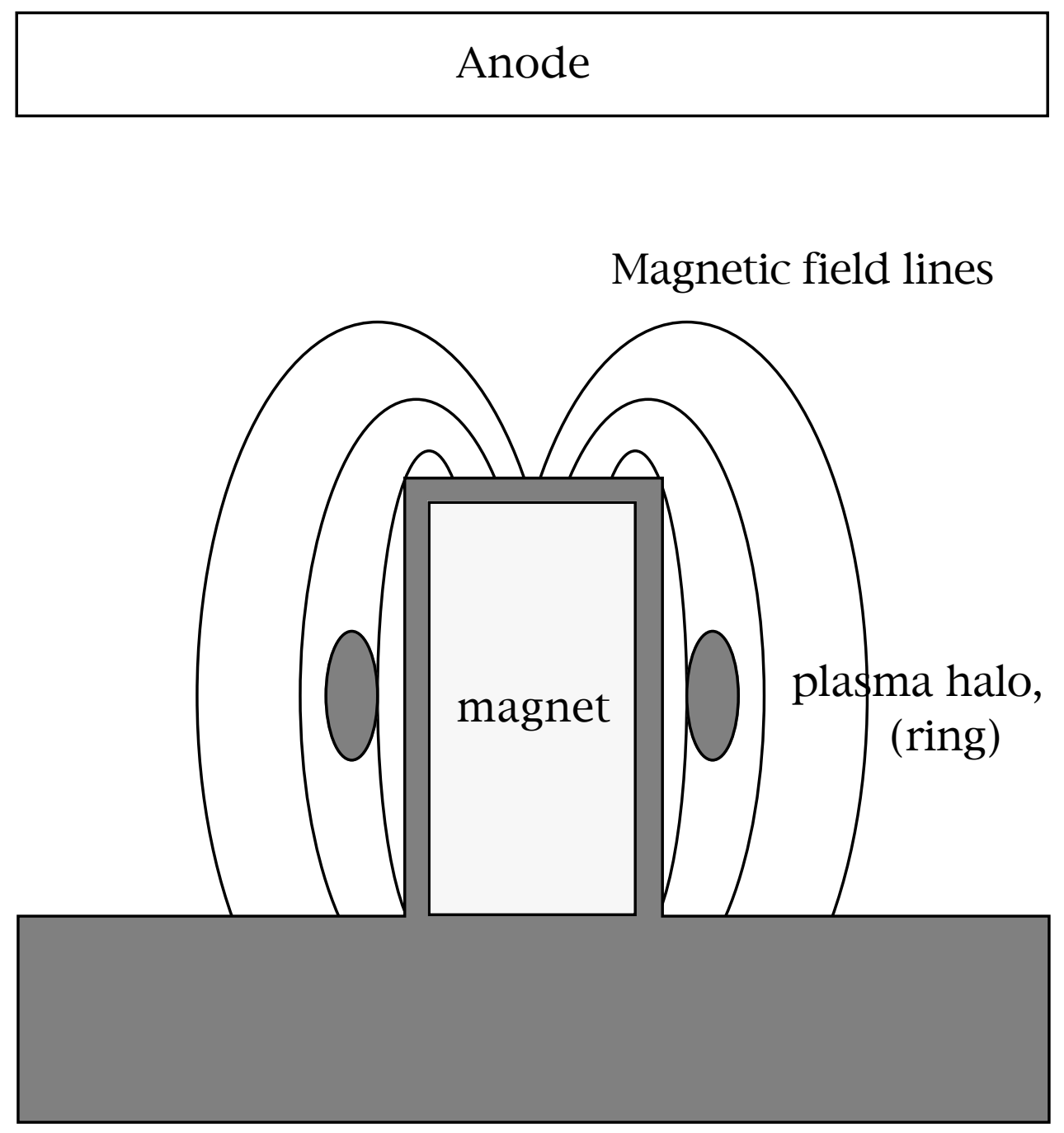

Fin cathode: magnet @ 90 to surface nearest halo

Figure 4: fin cathode 


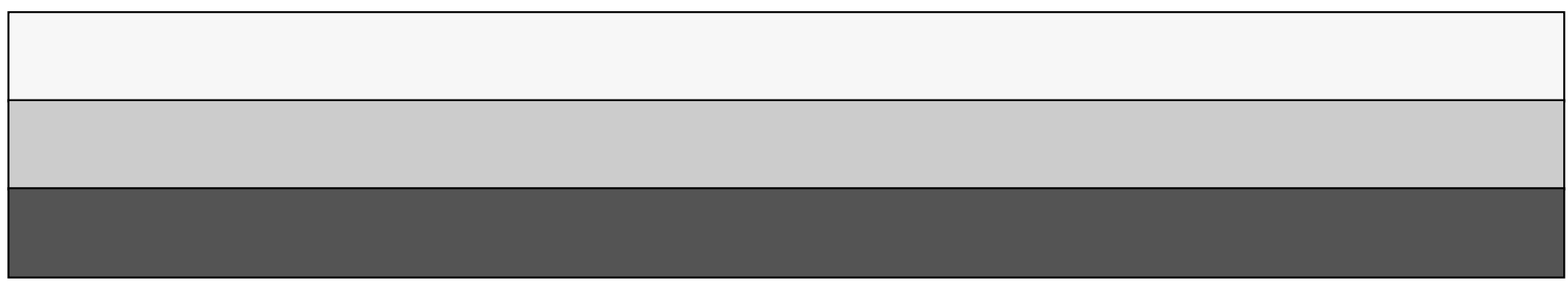

